\title{
UMA INTRODUÇÃO AO MODELO JUNGUIANO DA PSIQUÊ: A CONSTRUÇÃO DE UM INFOGRÁFICO
}

\section{AN INTRODUCTION TO THE JUNGUIAN MODEL OF PSYCHE: THE CONSTRUCTION OF A INFOGRAPHIC}

\author{
Ricardo Manhães ${ }^{1}$, Designer. \\ Victor Nassar², Ms. C. \\ Milton Luiz Horn Vieira ${ }^{3}$, Dr. \\ Francisco Antônio Pereira Fialho ${ }^{4}$, Dr. \\ (1) Universidade Federal de Santa Catarina \\ e-mail:ricomanhaes@gmail.com \\ (2) Universidade Federal de Santa Catarina \\ e-mail: victornassar@gmail.com \\ (3) Universidade Federal de Santa Catarina \\ e-mail: milton.vieira@ufsc.br \\ (4) Universidade Federal de Santa Catarina \\ e-mail:fap@gmail.com
}

Palavras-chave: Infográfico, Jung, Psiquê.

A complexidade de conceitos e termos utilizados por Jung sobre a psiquê humana tornam o seu ensino e aprendizagem em ambientes externos à psicologia bastante dificultado. Este artigo tem o objetivo relatar o processo de construção de um infográfico que visa tornar mais acessível a temática do modelo Junguiano da psiquê humana.

Key-words: Infographic, Jung, Psyche.

The complexity of concepts and terms used by Jung on the human psyche make his teaching and learning in environments outside of psychology very difficult. This paper aims to report the process of constructing an infographic that aims to make the theme of the Jungian model of the human psyche more accessible. 


\section{$16^{\circ}$ \\ ERGODESIGN USIHC CINAHPA}

$16^{\circ}$ Ergodesign - Congresso Internacional de Ergonomia e Usabilidade de Interfaces Humano Tecnológica: Produto, Informações Ambientes Construídos e Transporte

$16^{\circ}$ USIHC - Congresso Internacional de Ergonomia e Usabilidade de Interfaces Humano Computador

CINAHPA | 2017 - Congresso Internacional de Ambientes Hipermídia para Aprendizagem.

\section{Introdução}

O uso de infográficos tem como principal objetivo transmitir dados utilizando-se de imagens, textos e gráficos a fim de facilitar a compreensão do conteúdo pelo público (SALEH et al, 2015). O seu emprego no processo de ensino-aprendizagem é um tema que foi explorado por alguns autores. Os trabalhos consultados, em sua maioria, abordam o processo de organização das informações (LAPOLLI, 2014; KRAUSS, 2012) e outros que já abordam o uso de infográficos na sala de aula, utilizado ou criado pelo aluno, como meio de absorver o conteúdo a ser aprendido (KRAUSS, 2012). De acordo com Krauss (2012), o infográfico representa graficamente dados e ideias, instigando o cérebro a abordar um problema de vários ângulos, por isso seu uso em salas de aula se tornou uma alternativa para melhorar o processo de aprendizagem de conteúdos.

Rosa et al (2014) consideram o tratamento de conteúdos para a produção de um infográfico como uma prática multidisciplinar que no contexto da educação pode ser considerado como um recurso didático para chamar atenção sobre um determinado ítem dentro de um contexto maior. As autoras ressaltam que o uso destes recursos didáticos auxiliam o processo de ensino e aprendizagem, na medida em que permitem a conexão entre imagens e textos de forma sistematizada e organizada. Desta forma, a infografia torna possível a criação de cenários autoexplicativos, de fácil compreensão, com aprofundamento e com imensa quantidade de dados (LAPOLLI, 2014; PESSOA, 2012).

A complexidade de conceitos e termos envolvendo as teorias de Jung sobre a psiquê humana, tornam o seu ensino e aprendizagem em ambientes externos à psicologia, bastante dificultado. Alguns conceitos da teoria de Jung que ajudam a compreender o comportamento humano e as fases da vida, são muito utilizadas em áreas como Publicidade e Propaganda, Design e Marketing (SOBRINHO, 2015; SENS, 2015; SANTOS, 2014). Fernandes (2014) publicou recentemente um livro intitulado "Tipologias e arquétipos: a Psicologia Profunda como base para uma hermenêutica" cuja iniciativa foi de popularizar e democratizar a compreensão sobre conceitos complexos da psicologia, especificamente as tipologias de Jung, trazendo o conteúdo com uma linguagem mais acessível ao leitor não familiarizado com tais temas.

Desta forma, observa-se a necessidade de tornar estes conteúdos mais acessíveis, no que tange à facilidade do processo de ensino-aprendizagem. Para tanto, este artigo tem como objetivo relatar o processo de construção de um infográfico sobre a temática do modelo Junguiano da Psiquê humana para uso em processos de ensino e aprendizagem. Cabe ressaltar que, neste artigo, apenas serão trabalhados os conceitos introdutórios ao modelo Junguiano.

Foi realizado um levantamento bibliográfico sobre o modelo Junguiano da Psiquê humana, tendo como referência principal a obra do psicólogo Carl Gustav Jung intitulada "Arquétipos e o inconsciente coletivo", publicado no ano de 1976, e que é uma das referências no que tange os conceitos envolvendo as subpersonalidades humanas.

A parte aplicada desta pesquisa contemplou um projeto de design de informação desenvolvido em três etapas para a produção de um infográfico: 1) Levantamento, 2) Organização e 3) Construção. Estas etapas foram definidas em alinhamento às referências de Lupton (2013).

\section{0 modelo Junguiano da Psiquê}

Carl Gustav Jung foi um psiquiatra suiço, idealizador da psicologia analítica contribuindo com ideias que se perpetuam até hoje como: complexo, arquétipos, persona, interpretação dos sonhos, tipos de personalidade, individuação, entre outras (HOLLIS, 2013). Em 1976, Jung publicou o livro "Os arquétipos e o inconsciente coletivo", que consiste na reunião de trabalhos do autor publicados entre 1933 e 1955, em que são apresentados os conceitos de arquétipo e inconsciente coletivo.

De acordo com Jung (2002), o inconsciente pessoal
Realização:

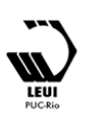




\section{$16^{\circ}$ \\ ERGODESIGN USIHC CINAHPA}

$16^{\circ}$ Ergodesign - Congresso Internacional de Ergonomia e Usabilidade de Interfaces Humano Tecnológica: Produto, Informações Ambientes Construídos e Transporte

$16^{\circ}$ USIHC - Congresso Internacional de Ergonomia e Usabilidade de Interfaces Humano Computador

CINAHPA | 2017 - Congresso Internacional de Ambientes Hipermídia para Aprendizagem. é o conteúdo esquecido por nós e que antes se encontrava em nosso consciente, e o inconsciente coletivo é conteúdos que nunca nos foi consciente, sendo adquiridos hereditariamente. Desta forma, o inconsciente coletivo é um conhecimento que é universal e idêntico em todos os seres humanos, por isso que Jung o denomina coletivo. Tanto o inconsciente pessoal como o coletivo, possuem conteúdos denominados arquétipos. Os arquétipos, podem ser compreendidos como formas préexistentes na psiquê humana (arcaicos e primitivos) e que são inicialmente inconscientes, mas que podem vir a se tornar conscientes.

Nossas representações arquetípicas se modificam conforme a necessidade de expressão do nosso inconsciente coletivo. "A reação necessária e da qual o inconsciente coletivo precisa se expressa através de representações formadas arquetipicamente (JUNG, 2002, p.31). Samuels, Shorter e Plaut (2003) explicam que arquétipos são "padrões de estruturação do desempenho psicológico ligados ao instinto", são imagens manifestadas do inconsciente coletivo, que através do tempo se repetem devido a sua origem primitiva no inconsciente humano.

Para compreender como são formados os arquétipos, é necessário compreender os termos que fundamentam o modelo Junguiano, como: self, alma, anima e animus, consciente e inconsciente, ego, persona, psiquê e sombra. Desta forma, foram reunidos no quadro abaixo uma breve explicação de cada termo com base nas obras de Jung.

- Self: Centro da personalidade total, que impulsiona cada ser na busca em direção ao seu Centro, a sua unidade, o seu crescimento. É o princípio ordenador da personalidade inteira. "não é somente o centro, mas também a circunferência total que abrange tanto o consciente como o INCONSCIENTE; é o centro dessa totalidade, como EGO é centro da mente consciente".

- Alma/Psiquê: É muitas vezes utilizada por Jung no lugar de psíque quando ele deseja se referir a um movimento que é mais profundo, enaltecendo sua variedade, pluralidade e impenetrabilidade. É a “totalidade de todos os processos psíquicos, conscientes como também inconscientes".

- Anima/Animus: São imagens psíquicas, ou seja, imagens da alma. É a figura interior de mulher contida no homem (anima) e a figura interior de homem contida na mulher (animus).

- Consciente: Oposto ao inconsciente. A obtenção de consciência é o resultado da reflexão sobre a experiência psíquica e sua retenção para que o indivíduo tenha a capacidade de combiná-la com outros aprendizados e encontrar o sentido na vida.

- Inconsciente: Relações que não são percebidas pelo Ego são de cunho inconsciente. São conteúdos mentais que são inacessíveis ao Ego.

- Ego: Centro da consciência. O Ego está fundido com o self, porém, é também separado do mesmo. O ego é desenvolvido ainda nos primeiros anos de vida, e é ele que analisa e capacita o self a atuar na vida cotidiana.

- Persona: É a máscara ou face escolhida pela pessoa para encarar o mundo. Para cada momento da vida podemos vestir uma ou mais personas que nos ajudarão a enfrentar tal momento da forma que consideramos a melhor.

- Psiquê: Compreende os processos conscientes e inconscientes, bem como os elementos pessoas e coletivos. É o que está em movimento e que se transforma.

- Sombra: É o lado negativo da personalidade, o lado obscuro que todo o ser humano carrega consigo. 


\section{$16^{\circ}$ \\ ERGODESIGN USIHC CINAHPA}

\section{Construção do infográfico}

\subsection{Etapa 1: Levantamento}

Com base na temática do modelo Junguiano da Psiquê, buscou-se na etapa de levantamento delinear o problema a ser resolvido, partindo de discussões dirigidas sobre o tema, em que foi possível definir os conceitos que seriam abordados no infográfico e mapas mentais, a fim de articular os conceitos e realizar conexões entre os mesmos.

Como documento de saída desta etapa, elaborou-se um mapa mental geral contendo todos os aspectos a serem abordados no infográfico (figura 1).

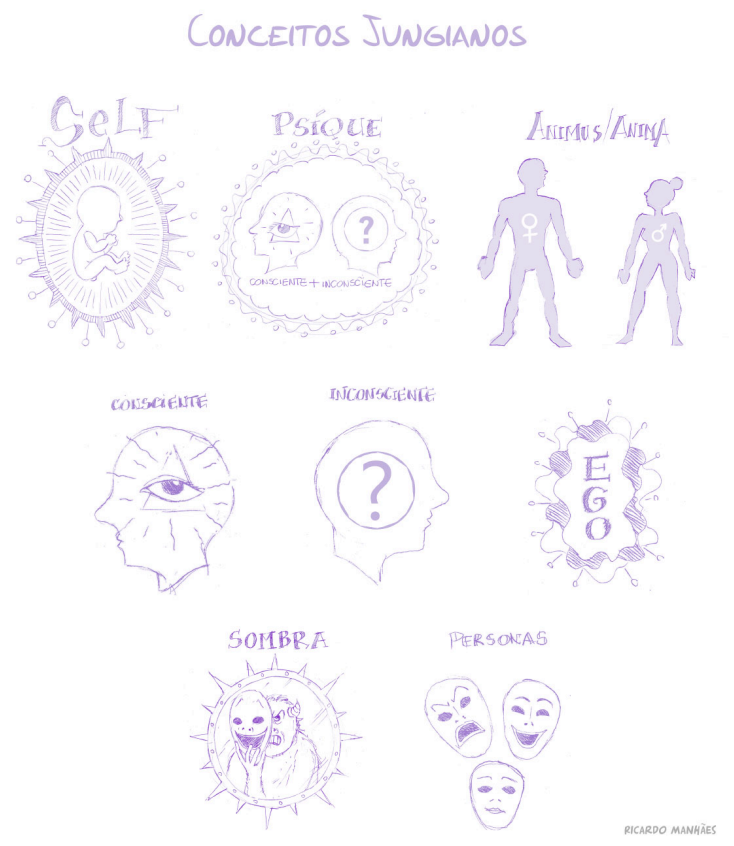

Figura 1. Esboços iniciais baseados nas concepções Jungianas.

\subsection{Etapa 2: Organização}

Nesta etapa foram utilizadas ferramentas voltadas a auxiliar o processo de idealização, de seleção e padronização dos termos e conceitos a serem abordados. Para isso, utilizou-se a colaboração que, de acordo com Lupton (2013, p.92), é uma ferramenta importante para se ter ideias. Segundo a $16^{\circ}$ Ergodesign - Congresso Internacional de Ergonomia e Usabilidade de Interfaces Humano Tecnológica: Produto, Informações Ambientes Construídos e Transporte

$16^{\circ}$ USIHC - Congresso Internacional de Ergonomia e Usabilidade de Interfaces Humano Computador

CINAHPA | 2017 - Congresso Internacional de Ambientes Hipermídia para Aprendizagem.

autora, "cada membro tem propriedade sobre algum aspecto do projeto, contribuindo para o grupo em um valioso conjunto de perspectivas e habilidades, mas cada um dos membros também está disposto a mesclar ideias individuais para criar a estrutura geral." Ela ainda salienta que o humor, a experimentação e a inteligência são essenciais para a elaboração de ideias cativantes.

Assim, adotou-se como procedimento os seguintes passos propostos por Lupton (2013):

- Todos os membros da equipe se reuniram em uma mesa com intuito de trocar ideias sobre o infográfico a ser desenvolvido;

- Foi identificado um dos membros para ser o líder da seção, a fim de manter o projeto sob controle;

- Foram repassadas as regras da seção, orientando os participantes a ouvir as ideias dos demais e expor as suas com respeito, e brincar, deixar fluir as ideias para atingir novas possibilidades.

Outra ferramenta utilizada foi o fluxo de ideias (Figura 2). Como documento de saída, elaborou-se um modelo simplificado do infográfico, utilizando desenhos e esboços iniciais, a fim de representar de forma simples as ideias discutidas e selecionadas pelo grupo. Este modelo serve de base para o andamento da próxima etapa.
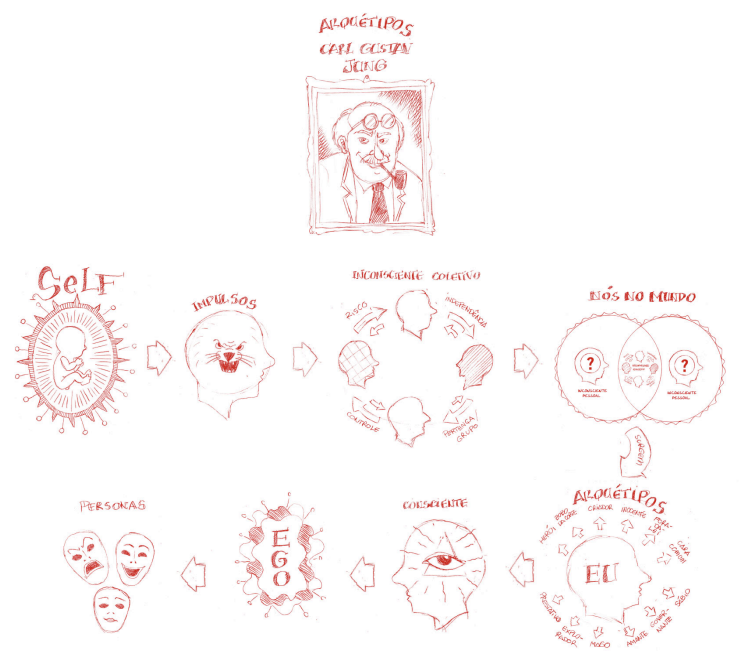

Figura 2. Fluxo das concepções Jungianas para a composição do infográfico. 


\section{$16^{\circ}$ \\ ERGODESIGN USIHC CINAHPA}

$16^{\circ}$ Ergodesign - Congresso Internacional de Ergonomia e Usabilidade de Interfaces Humano Tecnológica: Produto, Informações Ambientes Construídos e Transporte

$16^{\circ}$ USIHC - Congresso Internacional de Ergonomia e Usabilidade de Interfaces Humano Computador

CINAHPA | 2017 - Congresso Internacional de Ambientes Hipermídia para Aprendizagem.

\subsection{Etapa 3: Construção}

Na etapa de Construção, focada em como criar formas, foi elaborado o infográfico com base no modelo simplificado (Figura 3), a fim de facilitar a compreensão das teorias de Jung, utilizando-se como ferramenta a prototipagem em papel dos elementos que irão compor o infográfico. A prototipagem é testada e implementada até se alcançar o modelo final.

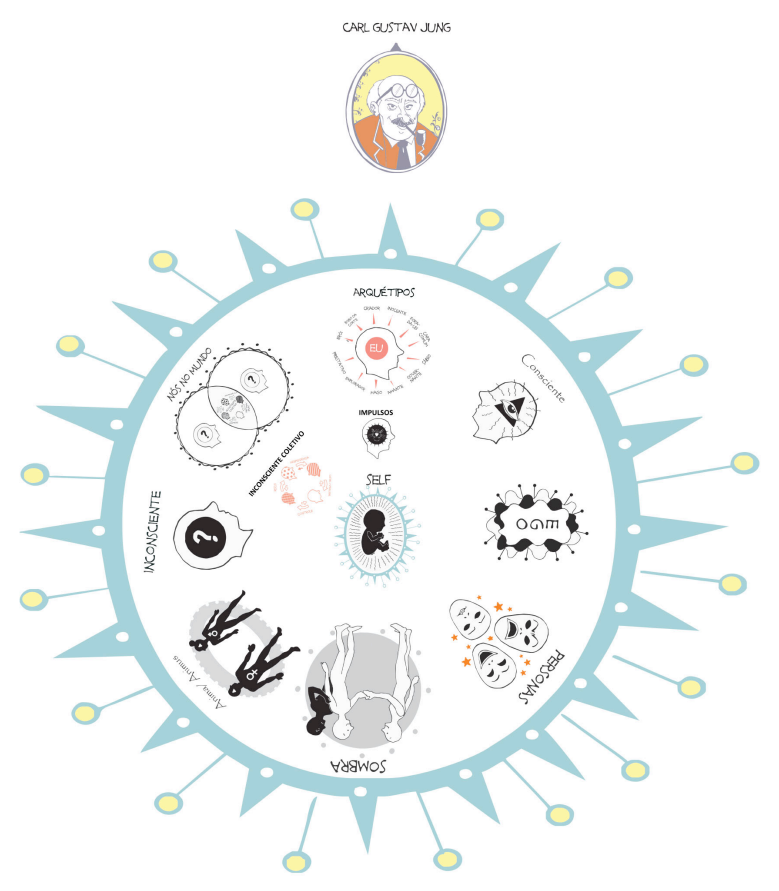

Figura 3. Construção do infográfico.

\section{Conclusão}

Como principal contribuição deste artigo, destacase a construção de um infográfico voltado à simplificação do processo de aprendizagem de alguns conceitos extraídos da psicologia Junguiana. Com o uso do infográfico desenvolvido, espera-se contribuir para maior disseminação destes conhecimento entre as mais variadas áreas do conhecimento, como: o design, o marketing, a administração, entre outros.

Salienta-se que o presente estudo se ateve a apenas alguns marcos teóricos presentes na psicologia Junguiana, de forma que há muitos outros pontos a serem abordados e que podem gerar trabalhos futuros. Desta forma, como futuros estudos, sugere-se um aprofundamento maior no que tange aos conceitos e teorias envolvendo a psicologia analítica de Jung. Assim também, novas formas de apresentar este conteúdo podem ser trabalhadas como vídeos, storytelling, histórias em quadrinhos, entre outros recursos disponíveis que podem auxiliar no processo de ensino e aprendizagem destes conteúdos. Sem dúvida é um campo relevante a ser explorado.

\section{Referências Bibliográficas}

FERNANDES, Ermelinda Ganem; FIALHO, Francisco Antônio Pereira. Tipologias e arquétipos: a Psicologia Profunda como base para uma hermenêutica - Coleção Jung sai pra rua. v. 1. Florianópolis: Insular, 2014. 264 p.

JUNG, Carl Gustav. Os arquétipos e o inconsciente coletivo. Tradução: Maria Luíza Appy, Dora Mariana R. Ferreira da Silva. $2^{\mathrm{a}}$ ed. Rio de Janeiro: Vozes, 2002.

KRAUSS, Jane. More than words can say infographics. Learning \& Leading with Technology, v:39, n:5, 2012.

LAPOLLI; VANZIN; ULBRICHT. Organização da informação em narrativas infográficas na web voltadas para o processo de ensino-aprendizagem Revista Brasileira de Design da Informação, v. 11, n. 1, p. $36-49,2014$.

LUPTON, Ellen; MILLER, A. Intuição, ação, criação. Barcelona: GG-Gustavo Gilli, 2013.

PESSOA, A. R.; MAIA, G. G. A infografia como recurso didático na Educação à Distância. Revista Temática, Ano VIII, n. 05,2012.

ROSA, E. C. S.; PANDINI, C. M. C.; RAFFAGHELLI, J. E. e BLEICHER, S. Produção de Material Didático para Educação a Distância. 1ed. Florianópolis: UDESC: UAB: CEAD, 2014.

SALEH, B; DONTCHEVA, M; HERTZMANN, A; LIU, Z. Learning style similarity for searching infographics. In: 41st annual conference on
Realização:

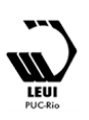




\section{$16^{\circ}$ \\ ERGODESIGN USIHC CINAHPA}

$16^{\circ}$ Ergodesign - Congresso Internacional de Ergonomia e Usabilidade de Interfaces Humano Tecnológica: Produto, Informações Ambientes Construídos e Transporte

$16^{\circ}$ USIHC - Congresso Internacional de Ergonomia e Usabilidade de Interfaces Humano Computador

CINAHPA | 2017 - Congresso Internacional de Ambientes Hipermídia para Aprendizagem.

Graphics Interface, 2015. Disponível em:

$<$ http://arxiv.org/abs/1505.01214>. Acesso em:

out. 2015.

SANTOS, C. M. Mitologia da Marca: imagens do inconsciente coletivo e diferentes perspectivas para a criação de estratégia de marketing. Ponto Revista Científica, v. 1, n. 1, 2014.

SENS, A. L.; M. V. MEURER; F. M. DE SOUZA; F. FIALHO. Contribuições dos arquétipos para a construção de projetos de design transmídia. In: Anais do XIX Congresso da Sociedade Iberoamericana de Gráfica Digital, Florianópolis, 2015.

SOBRINHO, A. B. F; DE OLIVEIRA, M. A. Arquétipos na publicidade: a mitologia no comercial televisivo Video Conferencing from Sony. Revista de Comunicação e Epistemologia, v.8, n.1, 2015.

\section{Agradecimento}

Agradecemos a UFSC, a CAPES e a FAPESC pela concessão de bolsas e a equipe do DesginLab, por ter colaborado com a pesquisa. 